\title{
CHOSEN ELEMENTS OF CIVILIZATIONAL SELECTION THEORY THIS IS WHY UNWILLING EVENTS ARE UNAVOIDABLE
}

Man has always lived in two spaces, natural environment and civilizational space. Civilizational space has been formed by man, is built up of all human activities, and has been created among others as human response to hazards. Variability of civilizational space causes the necessity of keeping up with changes. Things that were good yesterday today are of no value, which means they no longer protect from unwilling events. Description delay in relation to its constant change in civilizational space along with its complexity causes difference in interpretation. Occurrence of unwilling event is a sign that the accepted solution was bad and needs improvement. Thus, civilizational space is a source of hazards.

Man has always lived in two spaces. The first one, being the beginning of all that happened on Earth, has been created by natural environment. Here, it will be called natural space. The other space, civilizational, has been formed by man. Civilizational space, at first serving as a shield against blind forces of nature, has transformed along with civilizational development into independent existence. It was isolated out of natural environment characteristic of people only. The essence of the environment are human relations supported by science and technology. Without the civilizational space there would be no development of civilization. Creation of the civilizational space is an answer to hazards of life in natural environment in consequence of which people lost their lives. Building human relations was probably connected with ability to communicate among group individuals of first people. Common overcoming of hazards connected with famine, protection against stronger plunderer or the division of functions among the members of the society helped it to survive, that means it worked. Other solutions might have been checked, however, nothing can be said about them, as the societies no longer exist. That means their solutions did not work. Making assumption that such unsuccessful attempts had taken place is well justified. An observation of evolution of societies throughout their historical growth implies that such attempts have always been made. Some of them are exceptionally cruel but they are unavoidably verified by the civilizational evolution. Unavoidability is a common phenomenon in many domains. Natural selection is a good example here. Individuals unadapted to natural environment must suffer a defeat. There are no exceptions to this rule. Life in natural environment unavoidably made them create first organized societies. As mentioned before, it was a defensive reaction against challenges of natural environment. That was the right way to respond. To put it into modern terms, those people employed the strategy of response, which depends on mutual "stimulus-response" relations. The correct reaction protects against the effects of a given stimulus as long as the consequences are negative. The appropriate reaction to hazards caused by natural environment allowed man to survive. On account of what has been said so far it may be stated that the strategy of response is the original one in comparison to other reactions that have ever been observed. It may be said that this strategy is an inborn ability of humans and societies they constitute. Till present days it has brought exceptionally good results, however, as will be shown later, not always sufficient.

The correct reaction to hazards of nature influenced better organization of groups. Yet even then it was observed that reaction in "stimulus-response" relation only was not enough. How to react to hazards that are yet to come? Here magic appeared. People felt safer and were more self-assured in their actions knowing that all had been done to assure them succeed. Setting souls at rest through fulfilling rituals had a great advantage. It provided certainty of action as people deeply believed they were supported by supernatural forces. Such positive attitude worked well in fight with blind forces of nature. It was a good solution that lasted and transformed. The strategy of misfortune avoidance appeared. Hence, along with the strategy of response the strategy of prevention surfaced. The former one is said to be connected more with tools while the latter one with the spirit and its evolution. Both strategies have succeeded and exist up till now. They constitute the foundations of the civilizational space. Partially the strategy of prevention also helped man to detach from and become independent of nature. Building cities is a good example here.

A number of people feels comfortable in a city. It has its undeniable advantages. What is more, cities turned out to be a good solution for man and all the societies so far. Rural areas, even though closer to nature, also constitute oasis of human settlements. Natural disasters are no longer as dangerous as they used to be. Nevertheless, they are able to break manmade barriers and verify them often enough. The boundaries of the civilizational space created by man and natural space are in a state of flux. They change and in consequence they strive for balance of mutual adjustment. Each shift of balance always leads to disasters. It should be remem-

\footnotetext{
* J. M. Wolanin

The Main School of Fire Service, Warsaw 01-629 Slowackiego 52/54 Poland, E-mail: Jerzy.Wolanin@sgsp.edu.pl
} 
bered that natural space is primary and in consequence it provides the right direction to the evolution of civilizational space. The civilizational space will not replace natural space permanently. Even though the civilizational space influences the natural one the latter marks the direction of mankind development. Degradation of forests leads to floods, industrial gases destroy ozone in the atmosphere, and nuclear energy may be a cause of threats connected with radioactive contamination of environment. Those examples of interaction between the civilizational and natural space explicitly indicate obvious predominance of natural space in the struggle for search of the best solutions. Unfortunately the results come in form of disasters. How to avoid them? It is hard to give up on civilizational progress as such solution, negative in its nature, would also lead to disasters. There is some hope, however, in specific characteristics of struggle between civilization and nature. The idea is that on different levels of those struggles their effects are delayed in time. They occur after some time giving us the same a chance to undertake activities enabling counteraction to excessive civilization expansion. The chance can be used by researching mechanisms of concurrent phenomena of civilizational development and its influence on natural environment. Engaging in scientific research and making certain decisions may but do not have to lead to soothing the conflict between civilization and nature. The last claim does not have to refer to phenomena in global dimension. It stretches on each and every level and functions in local communities as well. Thus certain inertia of tension effects created on the point of junction of civilizational development and protection of natural environment allows better phenomena recognition and better performance of particular actions. It should be stressed here that symptoms of catastrophes appear much earlier in such cases. The whole problem is to be able to observe it at the right time and interpret adequately. For such reasons safety policy should be created no only in global dimension but in local one as well.

Undoubtedly safety policy belongs to the human sphere of action in the civilizational space. Appropriate safety policy assures people security. But on the other hand, how can we know that a given policy is appropriate? Only its functioning in thecivilizational space can verify it. It is helpless to hazards either natural or civilizational, as sooner or later tragedy will occur. Wrongly applied safety policy will always be negatively verified unlike correctly applied one which will last till it becomes insufficient and only then it will be negatively verified. All the considerations concerning safety policy that man has always employed refer to each and every aspect of human life. So the question is whether each human activity, as in the case of employing safety policy, is verified? And does negative verification always cause misfortune?

The analysis of the civilizational space characteristics will bring answers to those questions. The civilizational space is built up of all human activities. As it was mentioned before, it has been created as human response to hazards. This role is still present today. Complexity of human activities in the material as well as in spiritual sphere generates similar complexity in the civilizational space. Being independent, a single man creates his own existence. The distinctive feature of existence is its constant change. It is trans- formed by a constant activity of billions of people. Millions of tiny changes cause continual civilizational development. Some of those changes are more permanent than others. They bring certain things into the civilizational space but under the influence of other changes they simply disappear. Due to the civilizational space variability things that were good yesterday today are of no value and when they are no longer valued they just stop serving their turn. They do no longer protect from unwilling events or they do not fulfill requirements. Unfulfilling requirements causes discomfort which is categorized as one of less severe effects of unwilling events.

An unwilling event is defined as an event hazardous to life and/or human health, possession, environment as well as all social, economic and cultural relations of a given society or an event that does not achieve aims of undertaken actions.

Variability of the civilizational space causes the necessity of keeping up with the changes. Observing changes of natural environment around,is an everyday reality. Even in "safe" civilizational surroundings in order to survive one has to follow changes and adapt to them. Lack of $\mathrm{p}$ [ermanent adjustment always reveals unwilling events around. To avoid this humans incessantly investigate their surroundings and then analyze and describe it, i.e. they share experience with others. Description of civilizational settings may employ different forms, as many as the civilizational space has itself. Those can be scientific descriptions with research method records that aim at generalizing the binding laws. A description of reality is also expressed through all kinds of artistic forms. Does not classical music describe of sounds or is not a form of a world description in general? Actually, to description of setting belongs each information that is transformed in any way and any form. A description is a collection of gathered observations. This extremely differentiated means of sharing observations unfortunately has one fundamental feature. The result of civilizational space research influences the space itself and is strongly connected with it. At the time of exchanging given information the civilizational space described by the info is being transformed. It is due to the fact that the info has been spread around and has been functioning in minds of many people not mentioning the change in their consciousness. When multiplying this dependence by the infinite number of information exchanged in the whole world at any moment there is in fact a delay of knowledge about the civilizational space in relation to its factual state. Time is needed to describe a new reality. A new description changes unavoidably data described before. The process is continuous and ongoing. An analogy from physics can be helpful here. To see where exactly the electron is, first a photon reflected from the electron must be perceived by an eye. However, the photon reflecting from the electron moves it to another position. Hence, when one thinks he/she sees the electron it actually is already somewhere else. It may be said that phenomena occurring on an elementary particle level transform themselves to a description of the civilizational space. Just like in physics the principle of indeterminacy applies here. Thus, the civilizational space is elusive in its nature.

Description delay in relation to its constant change in the civilizational space along with its complexity causes difference in 


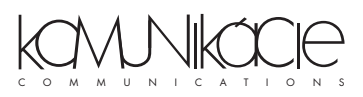

interpretation. Consequently, those differences influence adoption of various solutions concerning the civilizational space. Unfortunately, most of them are inadequate. Such a statement can be accepted with a high level of accuracy if the number of functioning solutions remaining in responsible time in relation to the number of solutions ever thought about is taken into consideration. Occurrence of an unwilling event is a sign that the accepted solution was bad. Accepting a bad solution is a result of elusive nature of the civilizational space. Unfortunately, this statement implies the following conclusion:

\section{Principle of indeterminacy in civilizational space description was, is, and will always be a source of hazards.}

So the civilizational space is a source of hazards. A space that has been created by humans to protect them became itself a source of hazards. Yet it is not the fault of man that he/she does not know how to use achievements of the civilizational space. Humans in their civilizational development have to accept bad solutions as they lack knowledge about the space because of the binding principle of indeterminacy. Lack of such knowledge causes that accepted solutions often do not fit into civilizational space and are negatively verified. Then negative selection takes place and causes that solutions are more adjusted to civilizational space. Such a phenomenon can be called civilizational selection.

Civilizational selection is a natural process of verification of accepted solutions depending on rejection of solutions not fitting into civilizational space and revealing through occurrence of unwilling events.

Civilizational selection is an unavoidable phenomenon due to the binding principle of indeterminacy. Unluckily, it also causes unavoidability of unwilling events occurrence on different scale. On the other hand, civilizational selection forces better accommodation to civilizational space. So for these reasons it is a phenomenon stimulating progress. The dynamics of changes in civilizational space influences the space itself. Vast variability of civilizational space accelerates civilizational selection. Unfortunately, acceleration means increase in the number of unwilling events occurrence that is often dramatic. For this reason every revolution is accompanied by such a great number of misfortunes. There is no difference whether it is industrial, social or political revolution. The dynamics of changes is high enough to be observed at once.

All that defines the essence of civilization is adjusted to civilizational space especially man and whole societies. Unacquainted with technology humans, when brought in contact with it, con- stitute an overt example of hazards. Civilizational space includes mutual relations between people. Here hazards may also occur when those relations are not fitted into civilizational surroundings, e.g. to well-established laws. Ideologies, organizational concepts, ways of handling business, forms of human organizational groups with common aims as well as cultural activity and media are all subjects to civilizational space adjustment. All human activities need to be accommodated into civilizational space. Each failure indicates lack of adjustment. Those facts even stronger confirm that civilizational space is a source of hazards itself.

Negative selection is not the only characteristic of civilizational selection. Civilizational selection is a stabilizer of proper solutions. Of course, "proper solution" is a relative notion and fits into the category of the best adjusted solution to civilizational space at a given time. However, some solutions are permanent while others are modified. It shows the existence of some universal laws in civilizational space. Such solutions become stable in consequence of civilizational selection. Very often history verifies stabilized solutions. Nevertheless, it does not deny commonly bounding civilizational selection. On the contrary, historical verification is a sign of civilizational selection. The connection between time and bad solution existence is hard to establish. Most probably it is connected with nature of the very thing being a bad solution. The longest ones of bad solutions to hold are ideologies. The reasons for that are subject to another inquiry.

Concluding, it may be claimed that there are several main reasons for developing hazards that are inseparably connected with surrounding reality. Firstly, the source of hazards are forces of nature always verifying ill-thought concepts. Secondly, the source of hazards is boundary of civilizational and natural space created by human beings. In this case nature verifies everything itself warning against bad solutions causing its devastation. Thirdly, the source of hazards is an immanent for civilizational space elusiveness arising in consequence of explicit inability to being described. It is a "genetic" feature of this space causing inadequacy of accepted solutions to its actual state. Fourthly, the source of hazards is the space itself due to psychological adjustment process to new civilizational conditions. Finally, the source of hazards are interpretations of observations concerning the conditions of civilizational space which are connected with constant monitoring by people and what follows accepting inadequate solutions. The latter occurs mostly on an individual decisions level.

The article was written after reading the Polish edition of "The End of Science" by John Horgan. I was inspired by chapter V: "The End of Evolutional Biology". 